\title{
Effectiveness of FACTS controllers and HVDC transmissions for improving power system stability and increasing power transmission capability
}

\author{
Molla Shahadat Hossain Lipu', Tahia Fahrin Karim² \\ ${ }^{1}$ School of Environment, Resources and Development (SERD), Asian Institute of Technology (AIT), Pathum Thani, Thailand \\ ${ }^{2}$ School of Engineering and Technology (SET), Asian Institute of Technology (AIT), Pathum Thani, Thailand
}

\section{Email address:}

lipuhossain@gmail.com(M. S. H. Lipu),fahrinkarim@yahoo.com(T. F. Karim)

\section{To cite this article:}

Molla Shahadat Hossain Lipu, Tahia Fahrin Karim. Effectiveness of FACTS Controllers and HVDC Transmissions for Improving Power System Stability and Increasing Power Transmission Capability. International Journal of Energy and Power Engineering. Vol. 2, No. 4, 2013, pp. 154-163. doi: 10.11648/j.ijepe.20130204.13

\begin{abstract}
With an increasing demand on energy and the construction of large generation units especially opening of electric power markets, it becomes more and more important to provide stable, secure, controlled and high quality electric power on today's environment. The regulatory constraints on the expansion of the transmission network has resulted in reduction of stability margins and increased the risks of cascading outages and blackouts. Among many possible solutions to overcome these challenges, FACTS devices and HVDC systems play an important role. These type of devices/systems have shown to be capable in stabilizing transmission systems, resulting in higher transfer capability. FACTS devices and HVDC transmissions have emerged as important solutions to help power systems to increase stability margins. Some of these power electronics-based components have the main function of controlling reactive power (SVC and STATCOM) and some others to control active power (as TCSC and CSC-HVDC transmission). All these devices are also capable of damping electromechanical oscillations. This paper presents a comprehensive review of operation of different types of FACTS controllers in the power system for stability enhancement in term of shunt compensators, series compensators as well as combinations of these two types of compensators. The paper also demonstrates different types of HVDC technology as well as its effectiveness to improve the voltage profile of power system.
\end{abstract}

Keywords: FACTS, TCSC, SVC, STATCOM, SSSC, UPFC, HVDC, Power System Stability

\section{Introduction}

In recent years, power demand has increased substantially while the expansion of power generation and transmission has been severely limited due to limited resources and environmental restrictions. As a consequence, some transmission lines are heavily loaded and the power system stability becomes a power transfer limiting factor. Flexible $\mathrm{AC}$ transmission systems (FACTS) controllers have been mainly used for solving various power system steady state control problems. However, recent studies reveal that FACTS controllers could be employed to enhance power system stability in addition to their main function of power flow control. For better utilization of the existing power system, to increase power transfer capability, installing FACTS devices become imperative [1, 2, and 3]. FACTS devices can control the parameter and variables of the transmission line, i.e. line impedance, terminal voltages, and voltage angles in a fast and effective way. The benefit brought about by FACTS includes improvement of system dynamic behaviour and thus enhancement of system reliability and loadability. However, their main function is to control power flows [4-7], provided that they are placed at optimal locations. These aspects are playing an increasingly significant role in the operation and control of the deregulated electricity market. The flexible AC transmission system is similar to high voltage DC and related thyristor developments, designed to overcome the limitations of the present mechanically controlled AC power transmission systems.

The increased interest in these devices is essentially due to two reasons. Firstly, the recent development in high power electronics has made these devices cost effective and secondly, increased loading of power systems, combined with deregulation of power industry, motivates the use of power flow control as a very cost-effective means of 
dispatching specified power transactions [8]. Several emerging issues in competitive power market, namely, as congestion management, enhancement of security and available transfer capability of the system, transmission pricing, etc. have been restricting the free and fair trade of electricity in the open power market. Moreover, it is important to ascertain the location for placement of these devices because of their considerable costs. The insertion of such devices in electrical systems seems to be a promising strategy to reduce the power flows in heavily loaded lines resulting in increased system loadability, low system loss, improved stability of the network and reduced cost of production as well as reduces mitigation of power quality problems such as voltage sag, swell \& interruption [9-12].

\section{Types of FACTS Controllers}

A schematic diagram of an $\mathrm{AC}$ interconnection between two systems is shown in Figure 1. The active power transmitted between the systems is defined by the given equation where $U_{1}$ and $U_{2}$ are the voltages at both ends of the transmission, $x$ is the equivalent impedance of the transmission, and $\delta_{1}-\delta_{2}$ is the phase angle difference between both systems. It is evident from Figure 1 that the transmitted power is influenced by three parameters: voltage, impedance, and voltage angle difference. FACTS devices can influence one or more of these parameters, as shown in the figure, and thereby influence power flow.

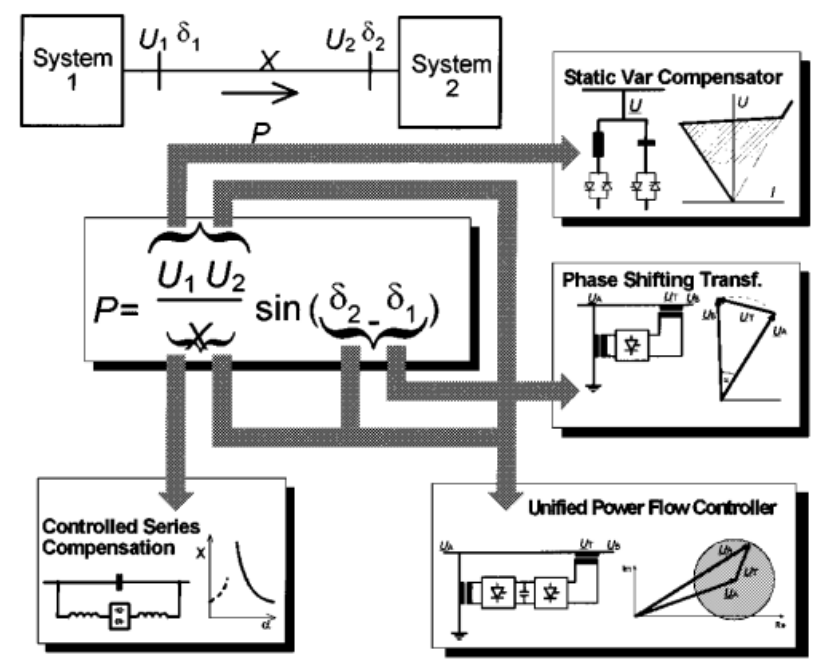

Figure 1. Power flow control and stability improvement in ac systems.

As the first FACTS controller listed, SVC has already been in use for two decades with excellent operating experiences. The demand for SVC has increased continuously as systems became more heavily loaded and problems arise regarding voltage control. The second task for SVC, to damp power oscillations and to increase the stability limit in long distance transmission systems, became important as new large transmission systems were built. In the future, instead of SVC, the STATCOM alternative (featuring GTO devices) will be used more frequently for shunt-connected controllers.

\subsection{Series Controllers}

The series controller could be a variable impedance, such as capacitor, reactor, or a power electronics based variable source of main frequency, synchronous and harmonic frequencies (or a combination) to serve the desired load. In principle, all series controllers inject voltage in series with the line. As long as the voltage is in phase quadrature with the line current, the series controller only supplies or consumes variable reactive power. Series controllers include SSSC, IPFC, TCSC, TSSC, TCSR, and TSSR [13].

\subsection{Shunt Controller}

The shunt controllers may be variable impedance, variable source, or a combination of these. In principle, all shunt controllers inject current into the system at the point of connection. Even a variable shunt impedance connected to the line voltage causes a variable current flow and hence represents injection of current into the line. As long as the injected current is in phase quadrature with the line voltage, the shunt controller only supplies or consumes reactive power. Any other phase relationship will involve handling of real power as well. Shunt controllers include SVC, STATCOM, TCR, TSR, TSC, and TCBR [14-15].

\subsection{Combined Series-Shunt Controllers}

This could be a combination of separate shunt and series controllers, which are controlled in a coordinated manner, or a UPFC with series and shunt elements. In principle, combined shunt and series controllers inject current into the system with the shunt part of the controller and voltage in series in the line with the series part of the controller. However, when the shunt and series controllers are unified, there can be a real power exchange between the series and shunt controllers via the proper link. Combined series-shunt controllers include UPFC, TCPST, and TCPAR [14-15].

\section{Static Series Compensators}

The variable series compensation is highly effective in both controlling power flow in the line and in improving stability. With series compensation the overall effective series transmission impedance from the sending end to the receiving end can be arbitrarily decreased thereby influencing the power flow. This capability to control power flow can effectively be used to increase the transient stability limit and to provide power oscillation damping [16].

\subsection{Thyristor-Switched Series Capacitor (TSSC)}

TSSR is an inductive reactance compensator, which consists of a series reactor shunted by a thyristor-controlled reactor to provide a stepwise control of series inductive reactance [17-18]. The basic element of a TSSC is a capacitor shunted by bypass valve shown in Figure 2 . The 
capacitor is inserted into the line if the corresponding thyristor valve is turned off, otherwise it is bypassed.
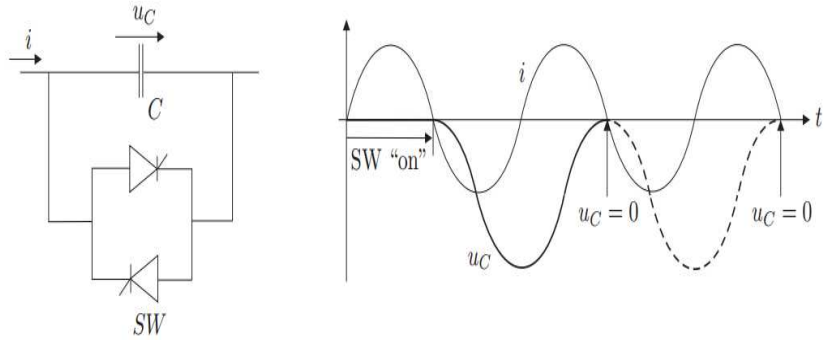

SW is allowed to turn on at $u_{C}=0$
Figure 2. Course of capacitor voltage for a basic element in a TSSC

A thyristor valve is turned off in an instance when the current crosses zero. Thus, the capacitor can be inserted into the line by the thyristor valve only at the zero crossings of the line current. On the other hand, the thyristor valve should be turned on for bypass only when the capacitor voltage is zero in order to minimize the initial urge current in the valve, and the corresponding circuit transient. This results in a possible delay up to one full cycle to turn the valve on. Therefore, if the capacitor is once inserted into the line, it will be charged by the line current from zero to maximum during the first half-cycle and discharged from maximum to zero during the successive half-cycle until it can be bypassed again [19].

\subsection{Thyristor-Controlled Series Capacitor (TCSC)}

TCSR is an inductive reactance compensator, which consists of a series reactor shunted by a thyristor-controlled reactor to provide a smoothly variable series inductive reactance [9], [15]. TCSC controllers use thyristor-controlled reactor (TCR) in parallel with capacitor segments of series capacitor bank shown in Figure 3. The combination of TCR and capacitor allow the capacitive reactance to be smoothly controlled over a wide range and switched upon command to a condition where the bi-directional thyristor pairs conduct continuously and insert an inductive reactance into the line [20].

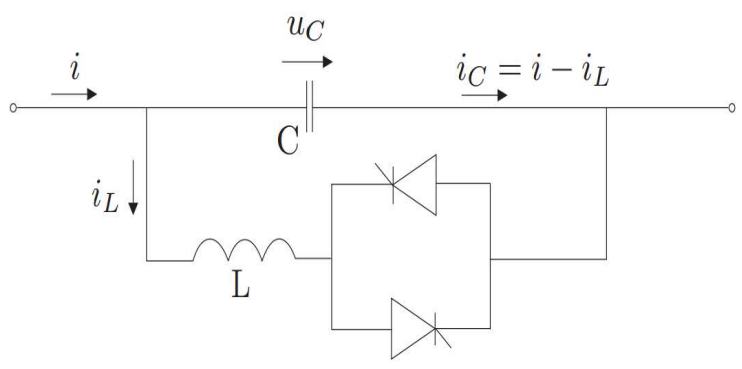

Figure 3: Thyristor-Controlled Series Capacitor (TCSC)

\subsection{GTO Thyristor-Controlled Series Capacitor (GCSC)}

An elementary GTO Thyristor-Controlled Series Capacitor consists of a fixed capacitor with a GTO thyristor valve that has the capability to turn on and off upon command [9]. The structure is given in Figure 4. The objective of the GCSC scheme is to control the AC voltage $u_{C}$ across the capacitor at a given line current $i$. When the GTO is closed $u_{C}$ is zero and when it is open $u_{C}$ reaches at its maximum value. For controlling the capacitor voltage, the closing and opening of the valve is carried out in each half-cycle which runs synchronously with the AC frequency. The GTO valve is stipulated to close automatically at the time when the capacitor voltage crosses zero. The turning off of the valve is controlled by a delay angle $\gamma$ with respect to the peak of the line current. Therefore, the adjustment of the capacitor voltage can only takes place once in each half-cycle [21-22].
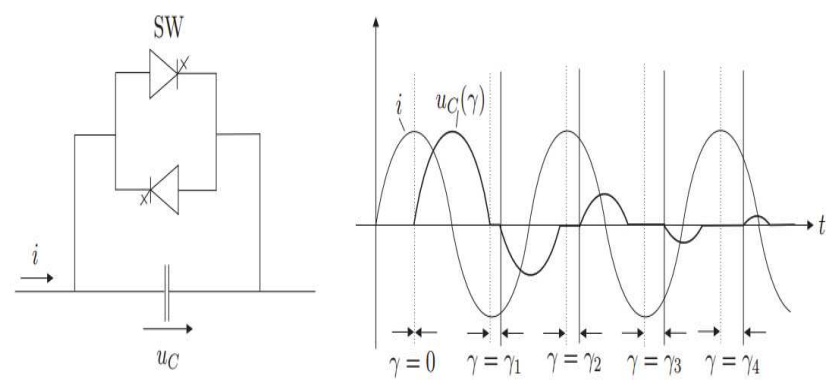

Figure 4. GTO-Controlled Series Capacitor

\subsection{Static Synchronous Series Compensator (SSSC)}

SSSC is a static synchronous generator operated without an external electric energy source as a series compensator whose output voltage is in quadrature with, and can be controlled independently with the the line current for the purpose of increasing or decreasing the overall reactive voltage drop across the line and thereby controlling the transmitted electric power [14]. The SSSC may include transiently rated energy storage or energy absorbing devices to enhance the dynamic behavior of the power system by additional temporary real power compensation, to increase or decrease momentarily, the overall real (resistive) voltage drop across the line. The principle of a SSSC is shown in Figure 5 for a two machine system.
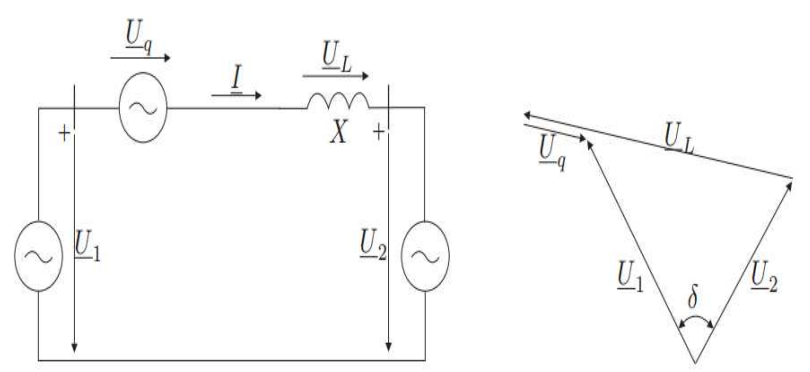

Figure 5. Synchronous voltage source for compensation

The phasor diagram shows that the voltage source increases the magnitude of the voltage across the inductance, i.e. the line, and therefore also increases the magnitude of the current I resulting in an increase in the 
power flow. This corresponds to the effect of a reactance placed in series. By making the output voltage of the synchronous voltage source $U q$ a function of the current $I$, the same compensation as provided by the series capacitor is accomplished: $U q=-j X C I$, Where $X_{C}$ is the reactance of the capacitor. However, with a voltage source it is possible to maintain a constant compensating voltage in the presence of variable line current because the voltage can be controlled independently of the current, i.e. the voltage source can also decrease the voltage across the line inductance having the same effect as if the reactive line impedance was increased. Thus, the SSSC can decrease as well as increase the power flow to the same degree, simply by reversing the polarity of the injected AC voltage. The series reactive compensation scheme, using a switching power converter as a synchronous voltage is termed Static Synchronous Series Compensator [21-22].

\subsection{Comparison of Series Compensators}

The SSSC is a voltage source type and the TSSC, TCSC and GCSC are variable impedance type series compensators. Resulting from the different structures there are essential differences in characteristics and features of these devices [9], [12].

In order to generate a controllable compensating voltage over an identical capacitive and inductive range which is independent of the magnitude of the line current, SSSC can be considered. On the other hand, TCSC can maintain maximum compensating voltage with decreasing line current over a control range determined by the current boosting capability of the thyristor controlled reactor. Besides, the SSSC has the ability to interface with an external DC power supply to provide compensation for the line resistance by the injection of active power as well as for the line reactance by the injection of reactive power. Moreover, SSSC with an energy storage increases the effectiveness of power oscillation damping by modulating the series reactive compensation to increase and decrease the transmitted power and by concurrently injecting an alternating virtual positive and negative real impedance to absorb and supply active power from the line.

SSSC and TCSC can be highly effective in controlling power flow in the line and in improving the dynamic behavior of the power system. But certain problems related to the transmission angle cannot be handled by series compensation. For example, the prevailing transmission angle may not be compatible with the transmission requirements of a given line or it may vary with daily or seasonal system loads over too large a range to maintain acceptable power flow in some affected lines. To solve these problems, phase angle regulators (PAR) or phase shifting transformers (PST) can be employed.

\section{Static Shunt Compensators}

Shunt compensation is used to influence the natural electrical characteristics of the transmission line to increase the steady-state transmittable power and to control the voltage profile along the line. As shunt compensation is able to change the power flow in the system by varying the value of the applied shunt compensation during and following dynamic disturbances the transient stability limit can be increased and effective power oscillation damping is provided. Thereby the voltage of the transmission line counteracts the accelerating and decelerating swings of the disturbed machine and therefore dampens the power oscillations. By placing the shunt in the middle of a line and therefore dividing the line into two segments, the voltage at this point can be controlled such that it has the same value as the end line voltages. This has the advantage that the maximal power transmission is increased [16].

\subsection{Static Var Compensator (SVC)}

SVC is a static Var compensator which is connected in parallel to transmission line. SVC acts as a generator/load, whose output is adjusted to exchange capacitive or inductive current so as to maintain or control specific power system variables. Static Var systems are applied by utilities in transmission applications for several purposes. The primary purpose is usually for rapid control of voltage at weak points in a network. Installations may be at the midpoint of transmission interconnections or at the line ends. SVC is similar to a synchronous condenser but without rotating part in that it is used to supply or absorb reactive power.

The basic structure of SVC is shown in Figure 6. The SVC is connected to a coupling transformer that is connected directly to the AC bus whose voltage is to be regulated. From Figure 5, SVC is composed of a controllable shunt reactor and shunt capacitor(s). Total susceptance of SVC can be controlled by controlling the firing angle of thyristors. However, the SVC acts like fixed capacitor or fixed inductor at the maximum and minimum limits [13], [15], [23]

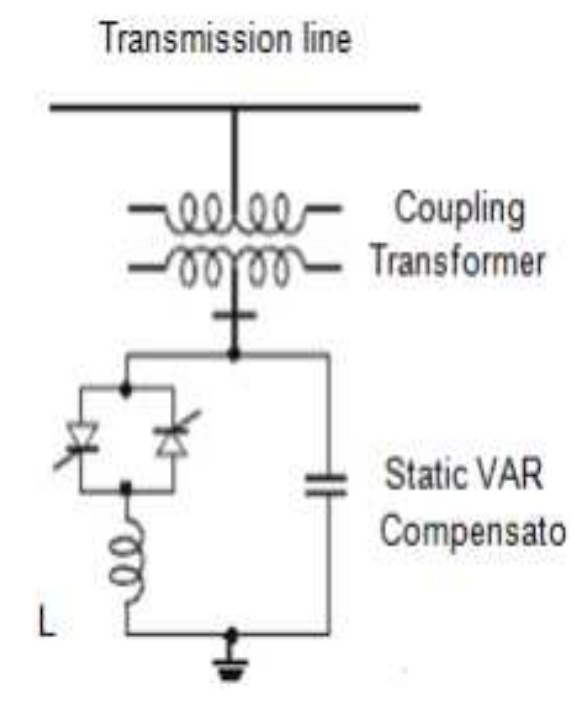

Figure 6. Basic structure of SVC 


\subsection{Thyristor-Controlled and Thyristor-Switched Reactor (TCR and TSR)}

TCR is a shunt-connected thyristor-controlled inductor whose effective reactance is varied in a continuous manner by partial-conduction control of the thyristor valve. TCR has been used as one of the economical alternatives of FACTS controllers [24]. An elementary single-phase thyristor-controlled reactor (TCR) is shown in Figure 7. The current in the reactor can be controlled from maximum to zero by the method of firing delay angle control. That is the duration of the current conduction intervals is controlled by delaying the closure of the thyristor valve with respect to the peak of the applied voltage in each half-cycle. For $\alpha=0$ 。 the amplitude is at its maximum and for $\alpha=90 \circ$ the amplitude is zero and no current is flowing during the corresponding half-cycle [25], [21], [22]. Like this the same effect is provided as with an inductance of changing value.
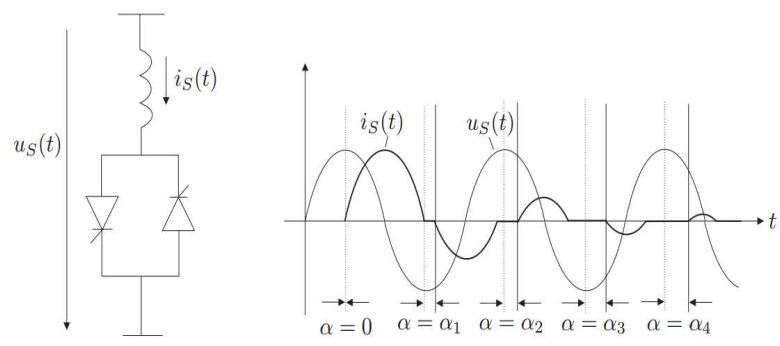

Figure 7. Thyristor-Controlled Reactor

A thyristor switched reactor (TSR) has similar equipment to a TCR, but is used only at fixed angles of 90 。 and $180^{\circ}$, i.e. full conduction or no conduction. The reactive current $i S(t)$ will be proportional to the applied voltage. Several TSRs can provide a reactive admittance controllable in a step-like manner [9], [18].

A single-phase thyristor-switched capacitor (TSC) is shown in Figure 8. The TSC branch can be switched out at a zero crossing of the current. At this time instance the capacitor value has reached its peak value. The disconnected capacitor ideally stays charged at this peak value and the voltage across the non-conducting thyristor varies in phase with the applied AC voltage.
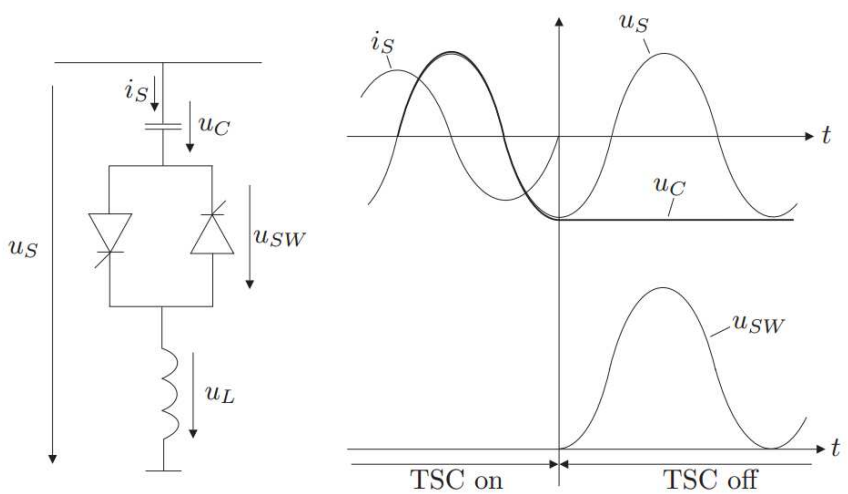

Figure 8. Thyristor-Switched Capacitor
Normally, the voltage across the capacitor does not remain constant during the time when the thyristor is switched out, but it is discharged after disconnection. To minimize transient disturbances when switching the TSC on, the reconnection has to take place at an instance where the $\mathrm{AC}$ voltage and the voltage across the conductor are equal, that is when the voltage across the thyristor valve is zero. However, there will still be transients caused by the non-zero $d u S / d t$ at the instant of switching, which, without the reactor, would result an instant current in the capacitor $\left(i_{S}=C . d u S / d t\right)$. The interaction between the capacitor and the current (and diS/dt) limiting reactor produces oscillatory transients on current and voltage [25], [21], [22], [14].

From these elaborations it follows that firing delay angle control is not applicable to capacitors; the capacitor switching must take place at that specific instant in each cycle at which the conditions for minimum transients are satisfied. For this reason, a TSC branch can provide only a step-like change in the reactive current it draws (maximum or zero). Thus, the TSC is a single capacitive admittance which is either connected to or disconnected from the AC system. The current through the capacitor varies with the applied voltage. To approximate continuous current variations, several TSC branches in parallel may be used.

\subsection{Static Synchronous Compensator: STATCOM}

STATCOM is a static synchronous generator operated as a shunt-connected static var compensator whose capacitive or inductive output current can be controlled independent of the AC system voltage. It provides voltage support by generating or absorbing reactive power at the point of common coupling without the need of large external reactors or capacitor banks [25], [26]. The basic voltage-source converter scheme is shown in Figure 9.

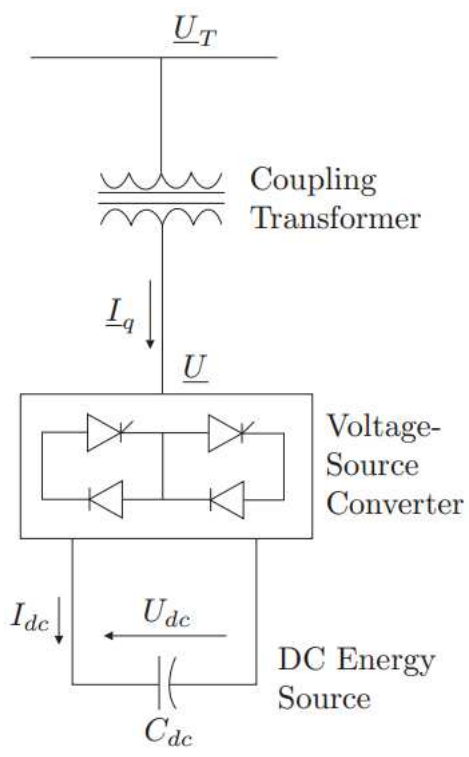

Figure 9. Static synchronous compensator: STATCOM 
The charged capacitor $C_{d c}$ provides a DC voltage to the converter, which produces a set of controllable three-phase output voltages with the frequency of the AC power system. By varying the amplitude of the output voltage $\underline{U}$, the reactive power exchange between the converter and the $\mathrm{AC}$ system can be controlled. If the amplitude of the output voltage $\underline{U}$ is increased above that of the AC system $\underline{U}_{T}$, a leading current is produced, i.e. the STATCOM is seen as a conductor by the $\mathrm{AC}$ system and reactive power is generated. Decreasing the amplitude of the output voltage below that of the AC system, a lagging current results and the STATCOM is seen as an inductor. In this case reactive power is absorbed. In the case of the DC capacitor, the energy stored in this capacitor would be consumed by the internal losses of the converter. By making the output voltages of the converter lag the AC system voltages by a small angle, the converter absorbs a small amount of active power from the AC system to balance the losses in the converter [17], [25], [26].

\subsection{Comparison of Shunt Compensators}

The function of SVC and STATCOM are very similar in their functional compensation capability, but in term operating principles, they are fundamentally different. A STATCOM controller is worked as a synchronous voltage source whereas a SVC is operated as a shunt-connected, controlled reactive admittance. The STATCOM has some advantages over SVC in terms of functional characteristics, better performance, and greater application flexibility [27].

The functional compensation capability of the STATCOM and the SVC are quite similar in the linear operating range of the V-I characteristic shown in Figure 10. But, when operation is done in the non-linear operating range, the STATCOM is able to control its output current over the rated maximum capacitive or inductive range independently of AC system voltage, whereas the maximum attainable compensating current of the SVC decreases linearly with AC voltage. Thus, the STATCOM is more effective than the SVC in providing voltage support under large system disturbances during which the voltage excursions would be well outside of the linear operating range of the compensator [28]. The ability of the STATCOM to maintain full capacitive output current at low system voltage also makes it more effective than the SVC in improving the transient stability. Moreover, the attainable response time and the bandwidth of the closed voltage regulation loop of the STATCOM are also significantly better than those of the SVC. In situations where it is necessary to provide active power compensation the STAT-COM is able to interface a suitable energy storage in large capacitor and battery from where it can draw active power at its DC terminal and deliver it as AC power to the system. On the other side, the SVC does not have this capability [25], [21] [29].

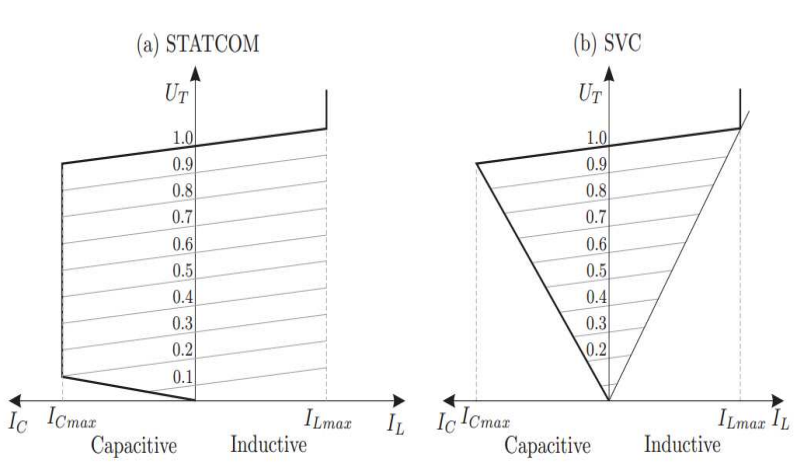

Figure 10. V-I characteristics of the STATCOM (a) and the SVC (b)

\section{Comparison between Shunt and Series Compensators}

The series-connected controllers impact the driving voltage and hence the current and power flow directly. Therefore, if the purpose of the application is to control the current/power flow and damp oscillations, the series controllers are several times more powerful than the shunt controllers.

The shunt controllers are like current sources. They draw from or inject current into the line. Thus, shunt controllers are applied to control voltage at and around the point of connection through injection of reactive current. Because STATCOMs have the capability to inject active as well as reactive current they are able to provide an even more effective voltage control and damping of voltage oscillations.

\section{Combined Compensator}

\subsection{Unified Power Flow Controller (UPFC)}

A combination of static synchronous compensator (STATCOM) and a static series compensator (SSSC) which are coupled via a common dc link, to allow bidirectional flow of active power between the series output terminals of the SSSC and the shunt output terminals of the STATCOM, and are controlled to provide concurrent active and reactive series line compensation without an external electric energy source. The UPFC, by means of angularly unconstrained series voltage injection, is able to control, con-currently or selectively, the transmission line voltage, impedance, and angle or, alternatively, the active and reactive power flow in the line. The UPFC may also provide independently controllable shunt reactive compensation [18].

The UPFC was developed for the real-time control and dynamic compensation of $\mathrm{AC}$ transmission systems. It is able to control all the parameters affecting power flow in the transmission line. Alternatively, it can independently control both the active and reactive power flow in the line. 


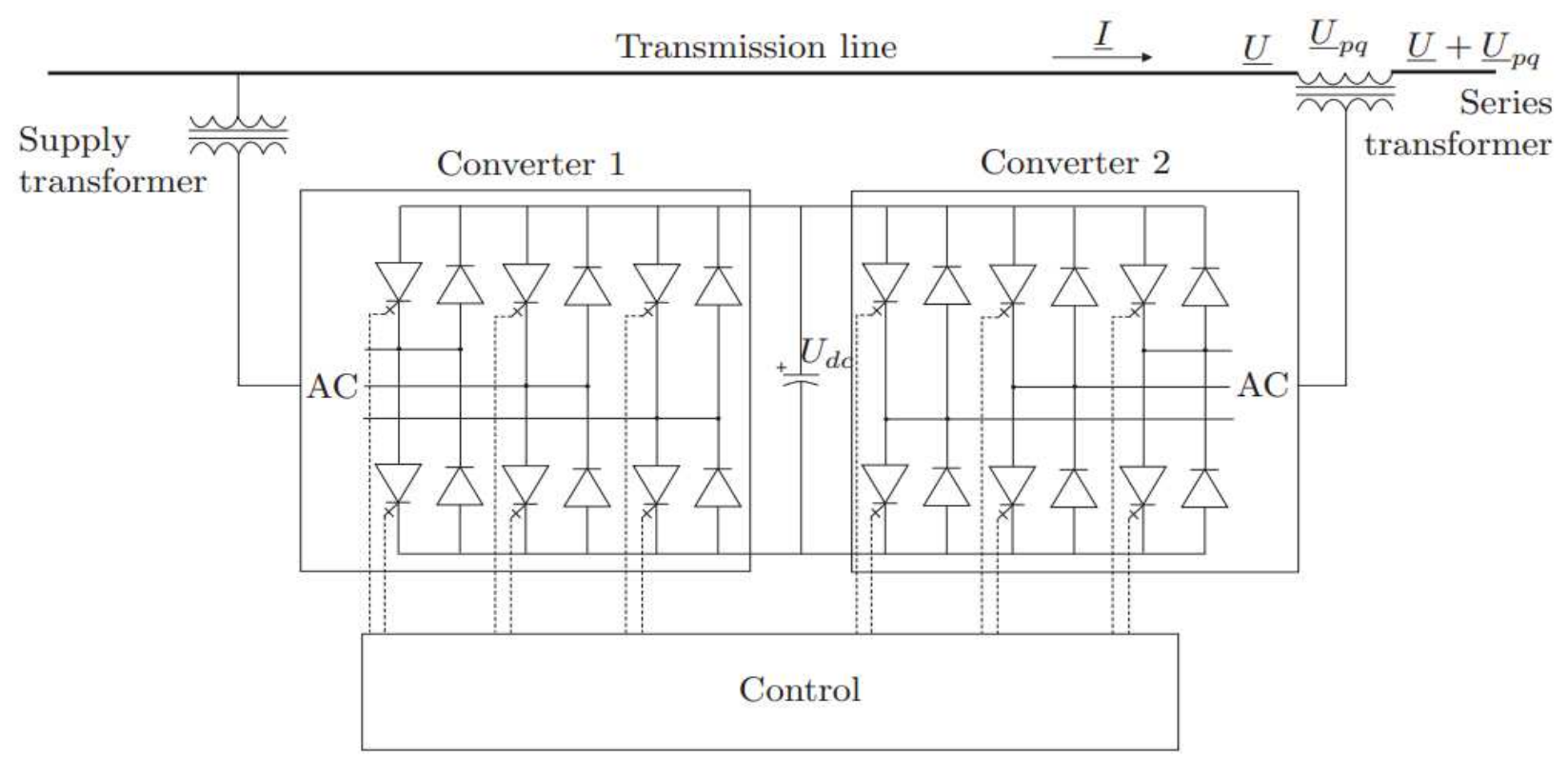

Figure 12. Implementation of UPFC

The UPFC is conceptually a synchronous voltage source with controllable magnitude $U_{p q}$ and angle $\rho$ placed in series with the line (see Figure 11). The voltage source exchanges both active and reactive power with the transmission system. But the voltage source can only produce reactive power, the active power has to be supplied to it by a power supply or a sink. This power supply is one of the end buses.

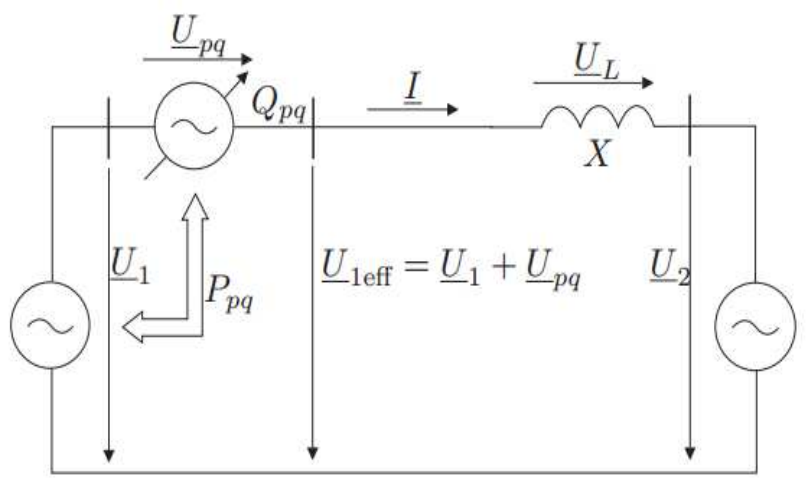

Figure 11. Concept of the UPFC in a two-machine power system

Presently, a UPFC consists of two voltage-source converters which are placed back-to-back and operated from a common DC link (DC storage capacitor) which is shown in Figure 12. The active power can freely flow in either direction between the AC terminals of the converters and each converter can generate or absorb reactive energy independently. Converter 2 injects the voltage $U p q$, which is controllable in magnitude and phase $(\rho)$, in series with the line and therefore acts as the voltage source. The reactive power exchanged at the $\mathrm{AC}$ terminal is generated by the converter internally. Opposed to this, the active power is converted into DC power which appears at the DC link as a positive or negative active power demand. This $\mathrm{DC}$ power demand is converted back to $\mathrm{AC}$ power by converter 1 and coupled to the transmission line bus via the supply transformer. Additionally, converter 1 can also exchange reactive power with the line, if necessary and provide independent shunt reactive compensation for the line [20], [29], [30].

\section{Application of FACTS}

In interconnected as well as in long-distance transmission systems technical problems occur which can limit the loadability and reliability of the system. Some problems result from normal changes and developments in power systems. A number of FACTS controllers are suitable for improving these technical problems. The application of these devices depends on the problem which has to be solved.

The technical benefits of the principal for dynamic applications of FACTS in addressing problems in transient stability, dampening, post contingency voltage control and voltage stability are summarized in Table-1 [17]. FACTS devices are required when there is a need to respond to dynamic (fast-changing) network conditions. The conventional solutions are normally less expensive than FACTS devices, but limited in their dynamic behavior. It is the task of the planners to identify the most economic solution. 
Table 1. Examples of use for FACTS

\begin{tabular}{llll}
\hline Subject & Problem & Corrective action & FACTS \\
\hline Voltage limits & Low voltage at heavy load & Supply reactive power & SVC, STAT-COM \\
& & Reduce line reactance & TCSC \\
& High voltage at low load & Absorb reactive power & SVC, STAT-COM \\
& High voltage following an outage & Absorb reactive power, prevent overload & SVC, STAT-COM \\
& Low voltage following at outage & Supply reactive power, prevent overload & SVC, STAT-COM \\
Thermal limits & Transmission circuit overload & Increase transmission capacity & TCSC, SSSC, UPFC \\
Load flow & Power distribution on parallel lines & Adjust line reactance & TSCS, SSSC \\
& & Adjust phase angle & UPFC, SSSC, PAR \\
& Load flow reversal & Adjust phase angle & UPFC, SSSC, PAR \\
Short circuit power & High short circuit current & Limitation of short circuit current & TCSC, UPFC \\
Stability & Limited transmission power & Decrease line impedance & TCSC, UPFC \\
\hline
\end{tabular}

\section{High-Voltage Direct-Current Transmission (HVDC)}

The tradition HVDC classic technology is used to transmit power for long distances via overhead lines or submarine cables with reduced losses. There is a breakpoint between ac and dc transmission distance, where after this point dc transmission is smarter and efficient. It also reduces the synchronous constraints between the two AC systems. It enhances steady state and dynamic stability of the AC system. A new technology named HVDC Light is used in recent 15 years which is based on VSC (Voltage Source Converters). HVDC Light has considerably higher dynamic performance compared to HVDC Classic, but still HVDC Classic I dominating for low cost bulk transmissions [28]. The basic structure of VSC-HVDC transmission is shown in Figure 13.

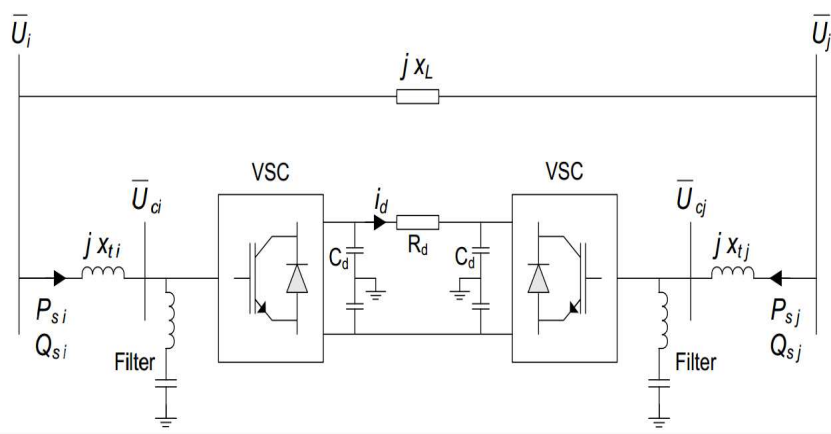

Figure 13. Basic Structure of a VSC-HVDC transmission

The objective of the HVDC Light model is to provide the correct interaction between ac and dc systems shown in Figure 14. It interacts with AC networks through the injected currents. The node voltages of the networks are determined by the Kirchoff's current law. It denotes an equation for each node, from which the node voltages can be solved, given the injected currents as function of the node voltages. Hence, the modeling objective is to provide equations of the HVDC Light, which gives the phasor of the AC current injected to the AC network as function of the phasor of the voltage of the AC node. The model is written for transient conditions. The model for steady state conditions is obtained by neglecting all time derivatives [32].

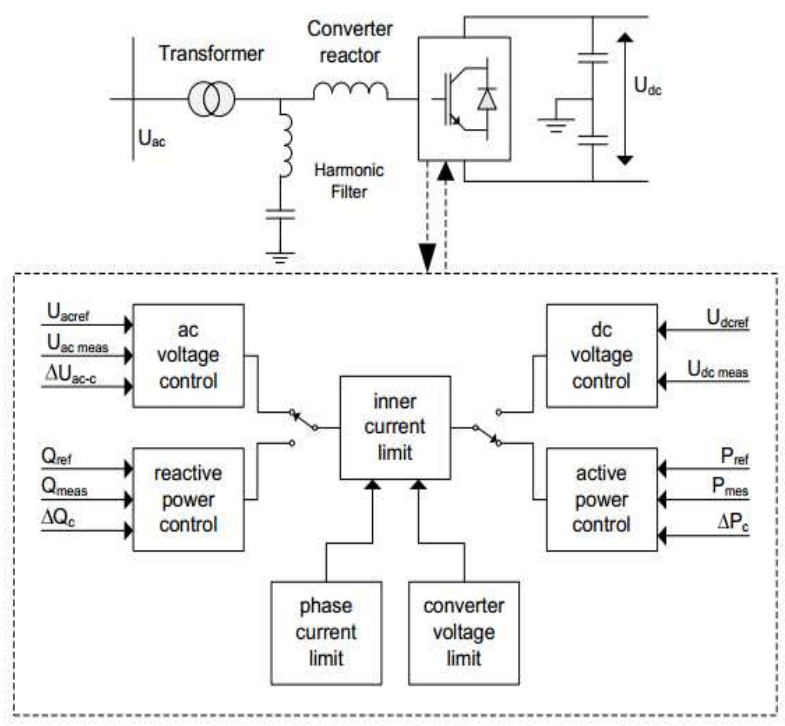

Figure 14. Overview control of HVDC Light Open Model

\subsection{Advantage of HVDC}

Modern HVDC systems combines the good experience of the old installations with recently developed technologies and materials. The result is a very competitive, flexible and efficient way of transmitting electrical energy with a very low environmental impact. It is important to remark that an HVDC system not only transmit electrical power from one point to another, but it also has a lot of value added which should have been necessary to solve by 
another means in the case of using a conventional AC transmission. The advantages of HVDC is illustrated below [31].

- No limits in transmitted distance. This is valid for both $\mathrm{OH}$ lines and sea or underground cables.

- Very fast control of power flow, which implies stability improvements, not only for the HVDC link but also for the surrounding AC system.

- Direction of power flow can be changed very quickly (bi-directionality).

- An HVDC link don't increase the short-circuit power in the connecting point. This means that it will not be necessary to change the circuit breakers in the existing network.

- HVDC can carry more power for a given size of conductor

- The need for ROW (Right Of Way) is much smaller for HVDC than for HVAC, for the same transmitted power. The environmental impact is smaller with HVDC.

- VSC technology allows controlling active and reactive power independently without any needs for extra compensating equipment.

- VSC technology gives a good opportunity to alternative energy sources to be economically and technically efficient.

- HVDC transmissions have a high availability and reliability rate, shown by more than 30 years of operation.

\section{HVDC Technology}

\subsection{Natural Commutated Converters}

Natural commutated converters are most used in the HVDC systems as of today. The component that enables this conversion process is the thyristor, which is a controllable semiconductor that can carry very high currents $(4000 \mathrm{~A})$ and is able to block very high voltages (up to $10 \mathrm{kV}$ ). By means of connecting the thyristors in series it is possible to build up a thyristor valve, which is able to operate at very high voltages (several hundred of $\mathrm{kV})$. The thyristor valve is operated at net frequency $(50 \mathrm{~Hz}$ or $60 \mathrm{~Hz}$ ) and by means of a control angle it is possible to change the DC voltage level of the bridge. This ability is the way by which the transmitted power is controlled rapidly and efficiently [31].

\subsection{Capacitor Commutated Converters (CCC)}

An improvement in the thyristor-based commutation, the CCC concept is characterized by the use of commutation capacitors inserted in series between the converter transformers and the thyristor valves. The commutation capacitors improve the commutation failure performance of the converters when connected to weak networks [31].

\subsection{Forced Commutated Converters}

This type of converters introduces a spectrum of advantages, e.g. feed of passive networks (without generation), independent control of active and reactive power, power quality. The valves of these converters are built up with semiconductors with the ability not only to turn-on but also to turn-off. They are known as VSC (Voltage Source Converters). Two types of semiconductors are normally used in the voltage source converters: the GTO (Gate Turn-Off Thyristor) or the IGBT (Insulated Gate Bipolar Transistor). Both of them have been in frequent use in industrial applications since early eighties. The VSC commutates with high frequency (not with the net frequency). The operation of the converter is achieved by Pulse Width Modulation (PWM). With PWM it is possible to create any phase angle and/or amplitude (up to a certain limit) by changing the PWM pattern, which can be done almost instantaneously. Thus, PWM offers the possibility to control both active and reactive power independently. This makes the PWM Voltage Source Converter a close to ideal component in the transmission network. From a transmission network viewpoint, it acts as a motor or generator without mass that can control active and reactive power almost instantaneously [31].

\section{Conclusion}

In this review, the role of FACTS controllers and HVDC tranmissions and its impact on power system stability enhancement was discussed and scrutinized. Different control design methodologies for designing FACTS and HVDC power flow controllers and power oscillations damping controllers in power systems have been illustrated. A comparative study between shunt and series compensator has also been discussed. Different types HVDC technology and its advantages has also been reviewed.

\section{References}

[1] L. Gyugi, "Power Electronics in Electric Utilities Static Var Compensators", IEEE Proceedings, Vol. 76, No. 4, April 1988, pp. 483-494.

[2] P. Moore and P. Ashmole "Flexible AC Transmission Systems Part-4, Advanced FACTS Controllers", Proc. Power Engineering Journal, April 1998, pp. 95-100.

[3] P. Moore and P. Ashmole, "Flexible AC Transmission Systems Part-3, Conventional FACTS Controllers", Proc. Power Engineering Journal, Aug 1997, pp. 177-183.

[4] P. Moore and P. Ashmole, "Flexible AC Transmission Systems Part-2, Conventional FACTS Controllers", Proc. Power Engineering Journal, Aug 1997, pp. 125-131.

[5] Y. H. Song and A. T. Johns "Flexible AC Transmission Systems", IEE London, T.J.I Ltd. 1999.

[6] L. Gyugyi "Solid State Synchronous Voltage Sources for Dynamic Compensation and Real Time Control of AC 
Transmission Lines", IEEE PES Summer Power Meeting Vancover, BC. Canada, 1993, pp. 1-26.

[7] G.D Galanos, C.I Hatziadoniu, Y-J Cheng and D. Maratukulam, "Advanced Static Compensator for Flexible AC Transmission”, IEEE Trans. On Power Systems, Vol. 8, No.1, Feb 1993, pp. 113-121.

[8] Shital B. Rewatkar and Shashikant G. Kewte, "Role of Power Electronics Based FACTS Controller SVC for Mitigation of Power Quality Problems", ICETET 2009, Second International Conference on Emerging Trends in Engineering \& Technology, 2009, pp.731-735

[9] Alok Kumar Mohanty, Amar Kumar Barik, "Power System Stability Improvement Using FACTS Devices" International Journal of Modern Engineering Research (IJMER), Vol.1, Issue.2, pp-666-672 ISSN: 2249-6645.

[10] Ch. Rambabu, Dr. Y. P. Obulesu, Dr. Ch. Saibabu, "Improvement of Voltage Profile and Reduce Power System Losses by using Multi Type Facts Devices" International Journal of Computer Applications (0975 -8887), Volume 13- No.2, January 201.

[11] R. Mihalic, P. Zunko and D. Povh, 1996, "Improvement of Stability using Unified Power Flow Controller," IEEE Transactions on Power Delivery, 11(1),pp. 485-491.

[12] R.Mohan Mathur and Rajiv K. Varma "Thyristor Based Facts Controllers For Electrical Transmission Systems", A John Wiley \& Sons, Inc, Publication, IEEE Press, New York 2001.

[13] A. Sode-Yome, N. Mithulananthan, Kwang Y. Lee, "A Comprehensive Comparison of FACTS Devices for Enhancing Static Voltage Stability" 1-4244-1298-6/07, 2007, IEEE.

[14] A. J. F. Kari, R. A. Byron, B. J. War, A. S. Mehraban, M. Chamia, P. Halvarsson, L. Angquist, CIGRE Paper 14/37/38-07, Paris (1992).

[15] A.-A. Edris, R. Adapa, M. H. Baker, L. Bohmann, K. Clark, K. Habashi, L. Gyugyi, J. Lemay, A. S. Mehraban, A. K. Myers, J. Reeve, F. Sener, D. R. Torgerson, R. R. Wood, IEEE Transactions on Power Delivery 12(4), 1848 (1997).

[16] R. Mihalic and I. Papic, "Static Synchronous Series Compensator-A Mean for Dynamic Power Flow Control in Electric Power Systems", Electrical Power System Research Vol. 45, No. 1, April 1998, pp. 65-72.

[17] N.G. Hingorani and L. Gyugyi. Understanding FACTS concepts and technology of flexible AC transmission systems. IEEE Press, New York, 2000.

[18] S.V. Ravi Kumar, S. Siva Nagaraju, 2007, "Transient Stability Improvement using UPFC and SVC," ARPN Journal of Engineering and Applied Sciences, 2(3), pp. 3845.

[19] Pavlos S. Georgilakis and Peter G. Vernados, "Flexible AC Transmission System Controllers: An Evaluation" Materials Science Forum, Trans Tech Publications, Switzerland, Vol.
670, pp 399-406, 2011

[20] R. Mihalic, P. Zunko and D. Povh, 1996, "Improvement of Stability using Unified Power Flow Controller," IEEE Transactions on Power Delivery, 11(1),pp. 485-491.

[21] Y.-H. Song. Flexible ac transmission systems (FACTS). The Institution of Electrical Engineers, London, 1999.

[22] Mehrdad Ahmadi Kamarposhti, Mostafa Alinezhad, Hamid Lesani, Nemat Talebi, "Comparison of SVC, STATCOM, TCSC, and UPFC Controllers for Static Voltage Stability Evaluated by Continuation Power Flow Method" 978-1-4244-2895-3/2008 IEEE Electrical Power \& Energy Conference.

[23] Mehrdad Ahmadi Kamarposhti, Mostafa Alinezhad, Hamid Lesani, Nemat Talebi, "Comparison of SVC, STATCOM, TCSC, and UPFC Controllers for Static Voltage Stability Evaluated by Continuation Power Flow Method" 978-1-4244-2895-3/2008 IEEE Electrical Power \& Energy Conference.

[24] S. Jalali, I. Dobson, R. H. Lasseter, G. Venkataramanan, IEEE Transactions on Circuits and Systems-I: Fundamental Theory and Applications 43(3), 209 (1996).

[25] R.M. Mathur and R.K. Varma. Thyristor-based facts controllers for electrical trans-mission systems. IEEE Press, Piscataway, 2002.

[26] Dong Shen and P.W. Lehn, "Modeling, Analysis and Control of a Current Source Inverter based STATCOM", IEEE Trans. On Power Delivery, Vol. 17, No.1, Jan. 2002, pp. 248-253.

[27] N. Mithulananthan, C.A. Canizares, J. Reeve, Graham J. Rogers, 2003, "Comparison of PSS, SVC and STATCOM Controllers for Damping Power System Oscillations," IEEE Transactions on Power Systems, 18(2), pp. 786-792.

[28] P. Kundur. Power system stability and control. McGraw-Hill, New York etc., 1994.

[29] D. Murali, Dr. M. Rajaram, N. Reka, "Comparison of FACTS Devices for Power System Stability Enhancement "International Journal of Computer Applications (0975 8887) Volume 8- No.4, October 2010.

[30] T. Yu and P.I. So. Coordinated control of TCSC and SVC for system damping improvement. International Conference on Electric Utility Deregulation and Restructuring and Power Technologies, 4-7 April, 2000, London.

[31] Roberto Rudervall, J.P. Charpentier, Raghuveer Sharma, "High Voltage Direct Current (HVDC)Transmission Systems Technology Review Paper"

[32] HÉCTOR F. LATORRE S., "Modeling and Control of VSC-HVDC Transmissions" Doctoral Thesis, Royal Institute of Technology, School of Electrical Engineering Electric Power Systems, Stockholm, Sweden, 2011 